Island Studies Journal, Vol. 9, No. 2, 2014, pp. 377 - 382

\title{
A response to McElroy and Lucas
}

\author{
Geoff Bertram \\ Victoria University of Wellington \\ New Zealand \\ Geoff.Bertram@vuw.ac.nz
}

\begin{abstract}
This brief paper comments on McElroy's Note, identifying one or two potential issues with its data and statistical method, but welcoming another contribution to the substantial body of islands scholarship that has appeared under McElroy's name. An important emerging topic for research is whether two key groups of small island economies - those that are now sovereign states and those that are (still) now non-sovereign territories - have followed diverging or parallel development paths since decolonization. Some evidence is noted pointing in both directions, leaving a wide-open field for future research.
\end{abstract}

Keywords: convergence, decolonisation, divergence, small island economies, political status.

(C) 2014 - Institute of Island Studies, University of Prince Edward Island, Canada.

\section{Introduction}

Jerry McElroy has pioneered the empirical study of how tourism and political status affect the levels of economic welfare achieved by small islands around the world. Adding Great Circle Distance to the mix carries his research program forward another step. As often happens, each two steps forward are accompanied by one step back: distance has stepped up to lead the list of explanatory variables; but, in the process, tourism (at least as proxied by the services share of GDP) now seems to have no significance in 'explaining' GDP per capita - which, for followers of McElroy's earlier work (McElroy \& Albuquerque, 1998; McElroy, 2002, 2003, 2006; Oberst \& McElroy, 2007; McElroy \& McSorley, 2007; McElroy \& Hamma, 2010), is a surprise.

\section{Concerns}

There is little detail about the regression experiments provided in McElroy's Note, which means that a number of common issues in small-islands statistical work are lurking in the shadows. Caution is always in order regarding the accuracy (especially for cross-country comparative purposes) of the World Factbook, which is a great resource for scholars to have, but sometimes wayward in its statistical practices.

Causality, more importantly, is unclear. At one point (at the end of the Scope and Method section) the Note seems to suggest that political status may actually be caused by geographical proximity to metropolitan patrons, which if true would make the use of STATUS as an independent explanatory variable questionable. However, none of the results presented in the Note confirm the tentatively-hypothesized causality from geographical location to political status, though changes in sample selection could well affect that result. 


\section{G. Bertram}

One notes, for example, that some geographically distant (from the relevant metropolis) but strongly politically affiliated islands are missing from the set of 35: Réunion, French Polynesia, New Caledonia, St Pierre et Miquelon, Martinique, Guadeloupe, the former Netherlands Antilles other than Aruba, Cayman Islands, Bermuda, and Falklands, to name a few. The reason is, as usual, gaps in the available data; but one needs always to be aware that data availability can easily translate to sample selection bias.

Intuitively, distance from a territory's main trading and financial partner is a problem per se. But McElroy's extensive work on the "propensity for dependence" (McElroy \& Albuquerque, 1995; McElroy \& Pearce, 2006; McElroy \& Parry, 2012) suggests that, all other things being equal, islands with affiliated status ought to do better than sovereign island states at any given distance from the metropole. This seems borne out to some extent by the Note's Equation 2. If indeed affiliation and distance share roughly equal responsibility for the modern level of economic welfare across the whole sample, as Equation 2 suggests, with one working in the opposite direction to the other, then the incentives for affiliation ought to be stronger the further an island is located from its metropole. One might then look for a clustering of affiliated territories at the periphery and of sovereigns at the core. Is this geographical pattern to be seen? If anything, the situation in the Pacific is the opposite: all of the most far-flung portions of the former British empire are now independent, except tiny Pitcairn.

\section{The origins of political affiliation}

This leads me to reflect on the origins of political affiliation. An economic model that ignored history might well "predict" that certain territories, or territories in certain geographic locations, would make "optimal" choices between sovereignty and affiliation, so that the realworld geography of political status would be an exercise in revealed preference. Great Circle Distance would then "explain" political status simultaneously with GDP per capita.

In fact, political status is largely determined by history, which is driven to only a limited extent (if at all) by rational exercises in economic optimization. We need, therefore, more richness in our historical accounts of small-island development. In particular the issue calls out for use of long-run time-series data to track how sovereign and affiliated territories have converged or diverged since decolonization (and possibly before). McElroy and Parry (2012) started down this path using panel data to demonstrate that, over the 25 years from 1985 to 2010, affiliated islands had been consistently more prosperous than sovereign island states, which raised the question of why sovereign independence had ever seemed attractive, at least until the mid-1980s. Their provisional answer was that, neither the payoffs to affiliation, nor the economic and political downsides of independence, were foreseeable at the start of decolonization in the 1940s, when, they argued, the then-colonies were starting out on a roughly equal footing. They wrote (McElroy \& Parry, 2012, p. 418),

Given the significant and long-lasting material advantage of non-sovereign over sovereign islands, why would so many of the latter have opted for independence prior to 1984? This issue bears further examination. Fragmentary evidence ... suggests the contrasts were much less visible and perhaps non-existent in the early post-war decades. ... [A]ccording to McElroy \& de Albuquerque (1995, p. 176), the recent affluence of the dependent territories 'is all the more remarkable, given the fact that a generation ago 
the performance indicators were decidedly reversed in favour of the larger, soon-to-be sovereign islands`.

I have recently been exploring this issue by gathering data back to decolonization and before on trade, life expectancy and some other variables for which information is available (Bertram, 2014). The work is very much at an early stage, but two early results seem to support an alternative possible story: that relative prosperity may have pre-dated choice of political status - in other words, poorer island territories became sovereign island states, rather than sovereign island states stayed poor or became poorer.

The first piece of evidence is the comparison (in Figure 1 below) of the paths of real Gross National Income of 26 small sovereign island states and 13 non-sovereign island territories. These two paths have followed roughly parallel tracks since the mid-1980s, with sovereign island states securing roughly double the income level of non-sovereign states, as one would expect from McElroy \& Parry (2012). But the two groups manifest convergence during the 1970s, followed by divergence in the early 1980s. This does not look like hard evidence that the two groups of island jurisdictions had embarked on their post-colonial trajectories - only a decade or two earlier - at equal levels of GNI. For that to be true, there would have had to be much more radical divergence of incomes during the 1960s - the first decolonisation decade for most of the sample - than anything seen after 1980

Figure 1: Ratio of population-weighted GNI per capita between 26 sovereign and 13 nonsovereign island economies, 1970-2010.

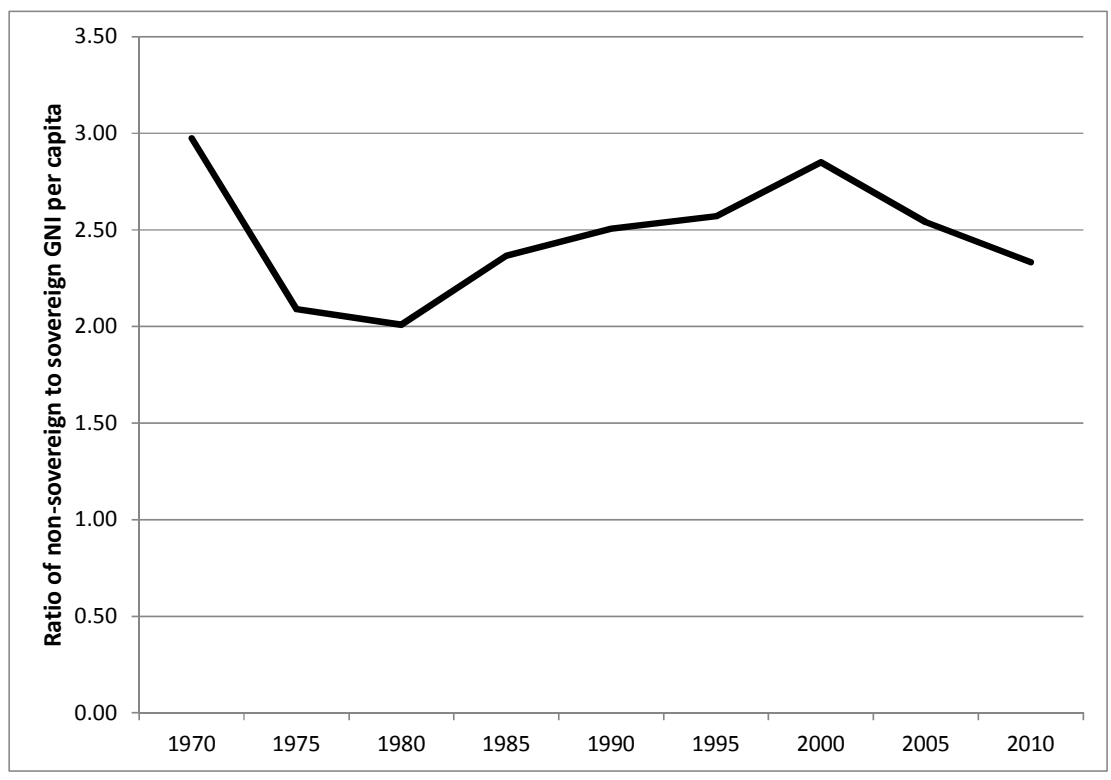




\section{G. Bertram}

The second piece of evidence is per capita imports, which provide the best proxy for per capita consumption back into the years before national accounts estimates of GDP and GNI are readily available. A population-weighted comparison of imports per head for 22 sovereign island states and 11 non-sovereign island territories since 1950 produces Figure 2, which could be used to support the view that the non-sovereign island territories started out well ahead, dramatically increased their lead over the last decades of the twentieth century, but then fell back in the 1990s and 2010s as their earlier sources of advantage weakened.

Figure 2: Population-weighted imports per head, US dollars, sovereign versus nonsovereign island economies.

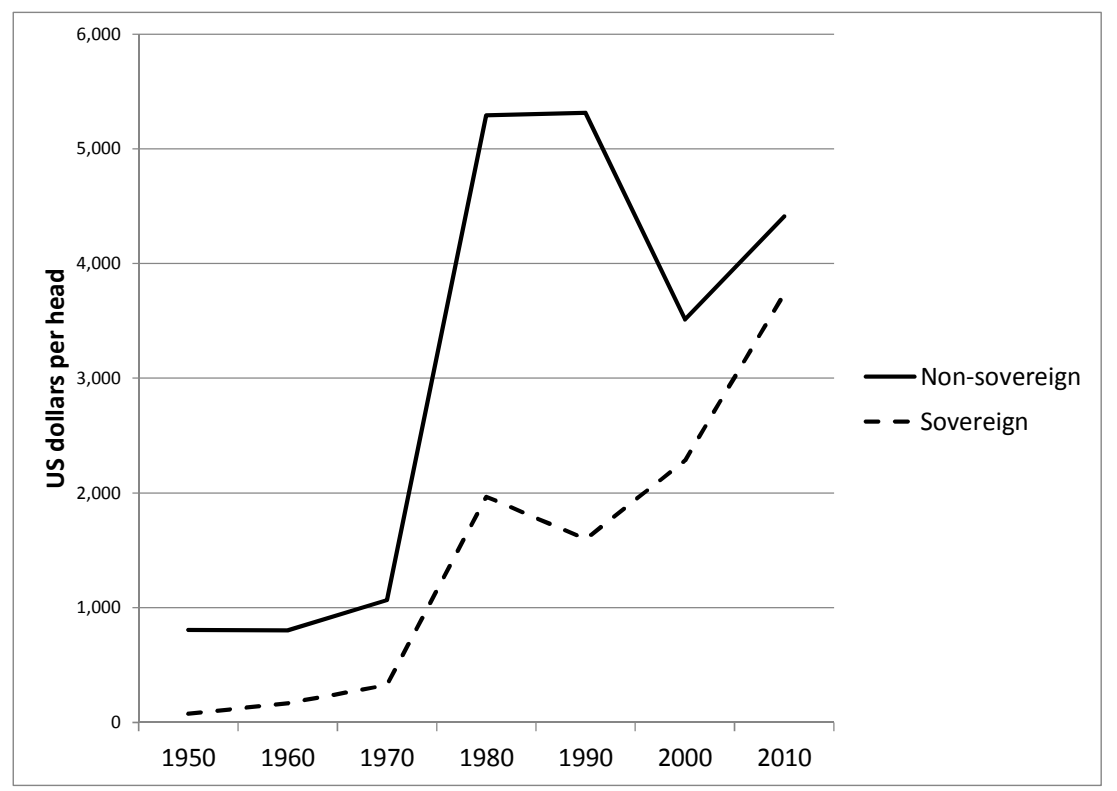

Both McElroy, and myself in previous work (Bertram, 2004), have advanced the hypothesis that affiliated political status has caused, rather than simply accompanied, greater prosperity than could have been achieved under sovereignty. Central to testing this theory is the issue of whether the two groups of island economies - those that are now sovereign states, and those (still) affiliated to metropolitan patrons - started out at similar levels of income, literacy, health status, life expectancy and so on at the end of the colonial era. There is evidence that provides some support for this view, particularly in the Caribbean where an excellent long-term data series from the early nineteenth century is now available (Bulmer-Thomas, 2012). Figure 3 summarizes Bulmer-Thomas's data on GDP per capita from 1960-1998; here, it does look as though political status may have affected growth paths. 
Figure 3: Real GDP per capita of 12 sovereign and 11 non-sovereign Caribbean island economies, 1960-1998.

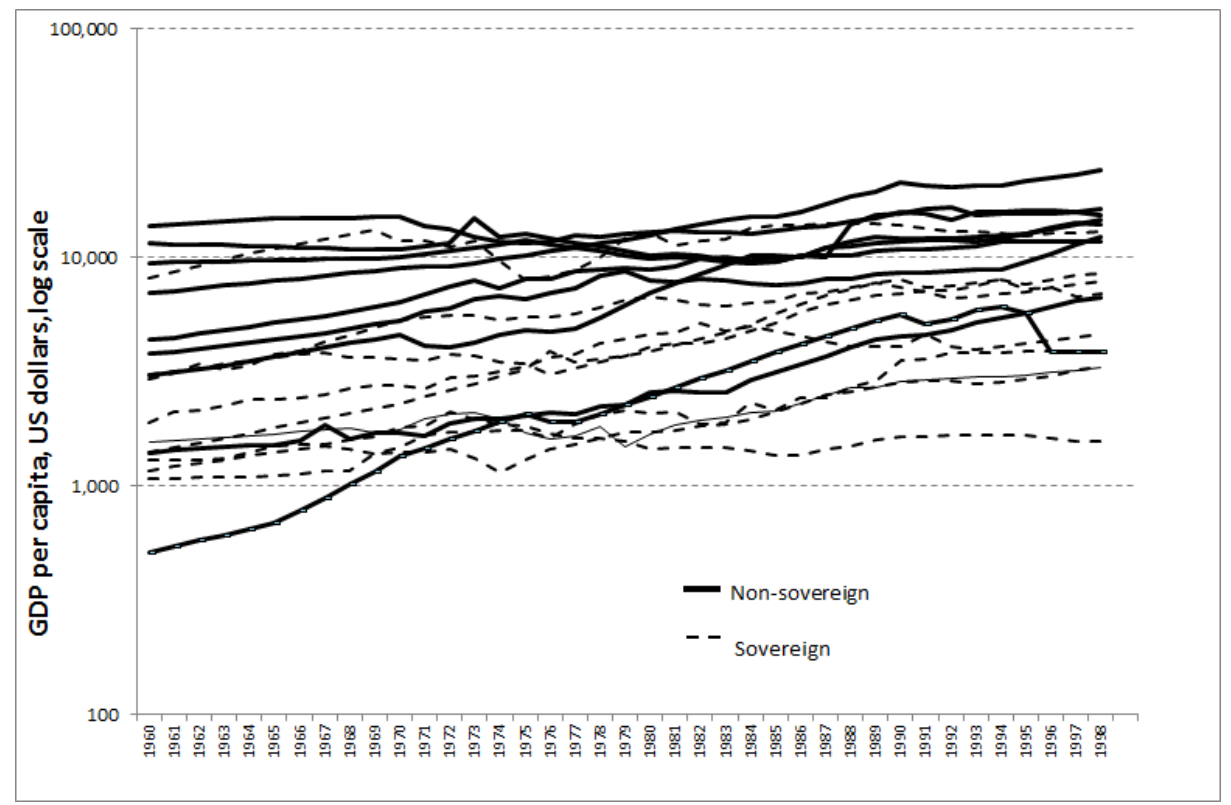

But, Figures 1 and 2 above tell a different story: particularly Figure 2, which goes back a decade before Figure 3 .

\section{Conclusion}

Clearly there is much more work needed to reconcile the apparent conflict between the two sets of data. The research programme flowing from the seminal work of McElroy and de Albuquerque (1995) still has plenty of life in it.

\section{References}

Bertram, G. (2014). Sovereignty and material welfare in small island jurisdictions. In A. Holz (ed.), Eine region im wandel: Politik \& macht in den pazifischen inselstaaten [A region in change: Policy and power in Pacific island states.] Publisher: tba.

Bulmer-Thomas, V. (2012). Economic history of the Caribbean since the Napoleonic wars. Cambridge: Cambridge University Press.

McElroy, J.L. (2002). The impact of tourism in small islands: a global comparison. In F. DiCastri \& V. Balaji (Eds.), Tourism, biodiversity and information, pp. 151-167. Leiden, The Netherlands: Backhuys Publishers.

McElroy, J.L. (2003). Tourism development in small islands across the world, Geografiska Annaler, 85B(4), 231-242. 
McElroy, J.L. (2006). Small island tourist economies across the life cycle. Asia Pacific Viewpoint, 47(1), 61-77.

McElroy, J. L., \& de Albuquerque, K. (1995). The social and economic propensity for political dependence in the insular Caribbean. Social and Economic Studies, 44(1), 167-193.

McElroy, J.L., \& de Albuquerque, K. (1998). Tourism penetration index in small Caribbean islands. Annals of Tourism Research, 25(1), 145-168.

McElroy, J.L., \& Hamma, P.E. (2010). SITEs revisited: socioeconomic and demographic contours of small island tourist economies. Asia Pacific Viewpoint, 51(1), 36-46.

McElroy, J.L., \& McSorley, K. (2007), Small islands economic strategies: aid-remittance versus tourism dependence. e-Review of Tourism Research (eRTR) 5(6), 140-148.

McElroy, J.L., and Parry, C.E, (2010), The characteristics of small island tourist economies. Tourism and Hospitality Research, 10(4), 315-328.

McElroy, J.L., \& Parry, C.E. (2012). The long-term propensity for political affiliation in island microstates. Commonwealth and Comparative Politics, 50(4), 403-421.

McElroy, J.L., \& Pearce, K. (2006). The advantage of political affiliation: dependent and independent small island profiles. The Round Table: Commonwealth Journal of International Affairs, 95(386), 529-539.

Oberst, A., \& McElroy, J.L. (2007). Contrasting socio-economic and demographic profiles of two, small, island, economic species: MIRAB versus PROFIT/SITE. Island Studies Journal, 2(2), 163-176. 